\title{
Estimation of Minimum Principal Stress from an Extended Leak-off Test Onboard the Chikyu Drilling Vessel and Suggestions for Future Test Procedures
}

\author{
by Weiren Lin, Koji Yamamoto, Hisao Ito, Hideki Masago, and Yoshihisa Kawamura
}

doi:10.2204/iodp.sd.6.06.2008

\section{Introduction}

To understand the physics of faulting and rupture propagation for the great M8-class Nankai earthquakes that recur approximately every 100 years, a comprehensive drilling project is underway: the Nankai Trough Seismogenic Zone Experiment (NanTroSEIZE; Tobin and Kinoshita, 2007), which is part of the Integrated Ocean Drilling Program (IODP). Stress levels along seismogenic faults must be known in order to understand processes controlling the timing, energetics, and extent of earthquake ruptures. For scientific drilling projects such as NanTroSEIZE, it is very important to determine the in situ stress state at the decollement and the mega splay fault in the Nankai Trough.

Preliminary experiments to determine the orientations and magnitudes of principal stresses in the Nankai Trough were undertaken during the NanTroSEIZE Stage 1 expeditions using borehole image analysis (stress-induced breakouts and tensile fractures; Kinoshita et al., 2008) and indirect, core-based methods such as anelastic strain recovery (ASR; Lin et al. 2006). These experiments will provide necessary and important information about in situ stress. However, to improve reliability and reduce experimental uncertainties in these stress determinations, it is necessary to have direct in situ measurements of stress magnitudes - in particular, the minimum principal stressat depth. These direct measurements are best obtained using methods involving the initiation and propagation of hydraulic fractures at depth, such as the traditional hydraulic fracturing test, a leak-off test (LOT), or an extended leak-off test (XLOT, sometimes ELOT) (Zoback et al., 2003). In the

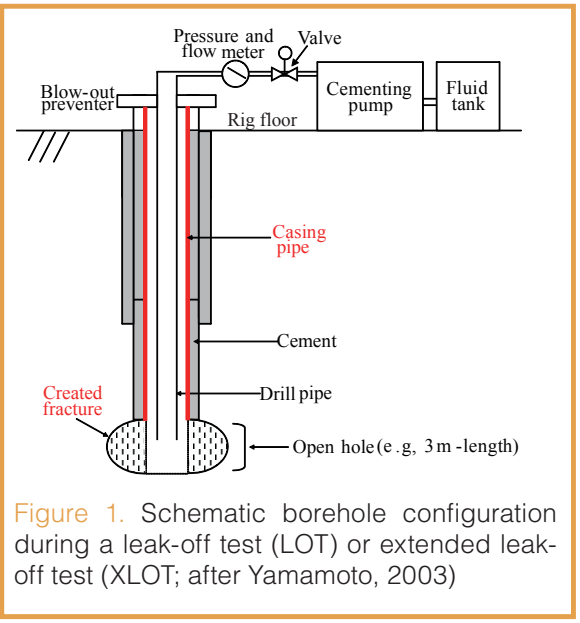

present paper, we aim to show that with the advent of the riser drilling vesselChikyu, the XLOT is applicable and effective in deep scientific ocean drilling projects.

During previous ODP expeditions and non-riser IODP expeditions, LOT or XLOT (which are sometimes used to determine drilling parameters such as optimal mud density) have not been conducted because the borehole was open to the seafloor. Thus, it has been impossible to pressurize a short interval of open hole below the casing as needed to conduct a LOT or XLOT (see below) without utilizing time-consuming and frequently unreliable drill-pipe-deployed packers. In contrast, the new drilling vessel Chikyu provides a riser-drilling capability that allows pressuring the entire casing string with drilling mud immediately after the casing is cemented in place. Therefore, NanTroSEIZE Stage 2 will present the first opportunity for a scientific ocean drilling program to use LOT or XLOT procedures without using a packer, providing direct information on the in situ magnitude of the minimum principal stress at minimal cost and risk.

In this study we will demonstrate the feasibility of using LOT and XLOT data acquired during the new riser-drilling program to determine stress magnitude. We will first describe LOT and XLOT procedures, and then use an XLOT data set that was acquired during the 2006 Shimokita shakedown cruise of the Chikyu drilling vessel to estimate the magnitude of minimum principal stress. We then recommend what we believe to be the optimum procedures for implementation of LOT-XLOT for determination of stress magnitude during future Chikyu riser-drilling programs.

\section{Description of the Tests}

A LOT is a pumping pressure test carried out immediately below newly set casing in a borehole (Fig. 1). It is similar to other pumping pressure tests known as the pressure integrity test, formation integrity test, or casing-shoe integrity test. Each of these tests has a different target pumping pressure. The LOT technique was originally developed in the oil industry to assess the "fracture gradient" of the formation (i.e., the maximum borehole pressure that can be applied without mud loss) and to determine optimal drilling parameters such as mud density (Kunze and Steiger, 1991). The LOT procedures are relatively simple. An XLOT is a more complex test with extended pressurizing procedures, as described in detail below. In future riser-drilling by Chikyu, it may be possible to regularly implement LOT or XLOT at each casing shoe immediately after casing has been run and cemented. 


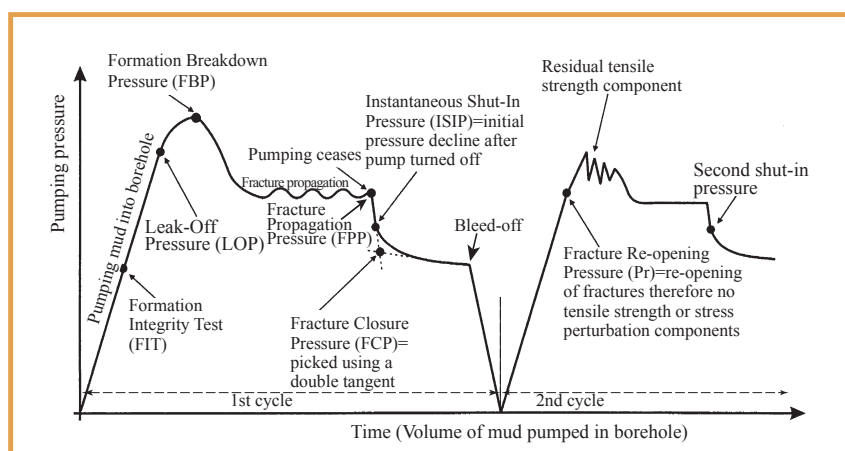

Figure 2. Idealized relationship between pumping pressure and time or volume of injected fluid during an XLOT (after White et al., 2002).

LOT and, in particular, XLOT procedures have been successfully and widely used to estimate the magnitude of minimum in situ horizontal stress (Addis et al., 1998; White et al., 2002; Yamamoto, 2003), mainly for the practical purpose of determining borehole stability during drilling operations. These data can be used for another important application-that is, to obtain in situ stress information that can be used in scientific objectives. In a similar case in which high borehole temperatures precluded use of a packer Hickman et al. (1998) conducted this kind of test to obtain in situ stress magnitude.

To carry out LOT or XLOT after setting casing and cementing, a short length (several meters) of extra open hole is drilled below the casing shoe. The casing shoe is then pressurized by drilling fluid delivered through drill pipe from a cementing pump set on the rig floor of the drilling vessel. The pressure at the casing shoe is equal to the sum of the hydrostatic pressure of the drilling fluid column and the ship-board pumping pressure. Figure 2 shows an idealized pumping pressure curve for XLOT (White et al., 2002).

Initially, pumping fluid into the borehole results in volumetric compression of the drilling mud column and elastic expansion of the casing string plus rock around the borehole. As the pressure in the borehole increases, the leak-off pressure (LOP) is reached when the relationship between pressure increase and volume of fluid pumped deviates from linear. This occurs when fluid begins to diffuse into the formation at a more rapid rate as the rock begins to dilate (Fig. 2). Generally, a LOT is a test that finishes immediately after LOP is reached.

An XLOT is an extended version of a LOT, but it is also similar to the hydraulic fracturing test used for stress measurement. During an XLOT, pumping continues beyond the LOP point until the pressure peaks at formation breakdown pressure (FBP). This creates a new fracture in the borehole wall. Pumping is then continued for a few more minutes, or until several hundred liters of fluid have been injected, to ensure stable fracture propagation into the undisturbed rock formation. The pumping pressure then stabilizes to an approximately constant level, which is called the fracture propagation pressure (FPP). Pumping then ceases (known as "shut-in”). The instantaneous shut-in pressure (ISIP) is defined as the point where the steep pressure decreases after shut-in deviates from a straight line. From our perspective, the most important pressure parameter is the fracture closure pressure (FCP), which occurs when the newly created fractures closes again. FCP is determined by the intersection of two tangents to the pressure versus mud volume curve (Fig. 2). The value of FCP represents the minimum principal stress (Yamamoto, 2003), because the stress in the formation and the pressure of fluid that remains in the fractures have reached a state of mechanical equilibrium. White et al. (2002) collected high-quality XLOT data and showed that both FCP and ISIP provide better estimates of minimum principal stress than LOP, although the difference in the values of LOP and ISIP was small in their study. In addition, ISIP is visually easier to determine than FCP. To end the test, the valve in rig floor is opened, and some of the fluid in the borehole flows back into the fluid tank (known as "bleed-off”).

To confirm the pressure values obtained from the initial XLOT, a second pressurization cycle is warranted (Fig. 2). Because a fracture has been created by the first execution of XLOT, in the second cycle the pressure at the time of re-opening of the fracture corresponds approximately to the FPP of the first cycle. In general, it is advisable to conduct additional pressurization cycles beyond the second cycle in order to confirm that stable values of FCP and ISIP have been obtained.

\section{An Extended Leak-off Onboard the Chikyu}

During the Shimokita shakedown cruise (6 August to 26 October 2006), an XLOT was conducted onboard the Chikyu. The test was carried out at a depth of 525 meters below seafloor (mbsf) in $1180 \mathrm{~m}$ water depth; fluid density (seawater) was $1.030 \mathrm{~g} \cdot \mathrm{cm}^{-3}$, and the injection flow rate was $0.5 \mathrm{bbl} \cdot \mathrm{min}^{-1}$ (about $80 \mathrm{~L} \cdot \mathrm{min}^{-1}$ ). Pressure and flow rate were recorded at the surface, using a sample rate of $5 \mathrm{~min}^{-1}$. The resolution of the pressure measurements was $1 \mathrm{psi}$ (about $7 \mathrm{kPa}$ ) its accuracy is less than $\pm 37 \mathrm{psi}$ (about $\pm 259 \mathrm{kPa}$ ). Because the main objectives of the first drilling operation test of the Chikyu during the Shimokita shakedown cruise were confirming basic drilling procedures, pure sea water was used, and rough measurement conditions were adopted for the preliminary XLOT. At the Shimokita site, core samples were retrieved only to a depth of 365 mbsf. However, the lithology at the XLOT depth was identified from cuttings analysis as volcanic tuff.

The fluid pumping rate was constant, and pumping was stopped immediately after formation breakdown (Fig. 3). About 400 liters $(2.5 \mathrm{bbl})$ of seawater was injected into a length of about $3 \mathrm{~m}$ of uncased borehole for about $6 \mathrm{~min}$, thus creating a fracture in the borehole wall. After shut-in, pressure was monitored for about $14 \mathrm{~min}$ and then released 
(bleed-off). Although two cycles were tried, only a data set of the first cycle was successfully obtained in this test.

The processes of formation breakdown and stable fracture propagation were not clearly evident in this test (compare Figs. 2 and 3). Moreover, the pressure versus time curve was not smooth, owing to the large data sampling interval during the pumping and monitoring processes and the relatively poor accuracy of the rig-floor pressure recorders. Thus, it was hard to pick the FCP with any confidence, as this requires that two tangents be drawn to the pressure decay curve. Instead, we estimate that the magnitude of the minimum principal stress lies between the pressure at the moment the pumps were turned off, which should be a close upper bound to the ISIP since we are conducting the test with low-viscosity sea water, and our estimated value for the FCP, obtained as best we could using a bi-linear tangent approach (Fig. 3). In this manner, we estimate that the magnitude of the minimum principle stress is $18.3-18.5 \mathrm{MPa}$. For comparison, we estimated the magnitude of vertical stress at the test depth from the density of the formation. An average formation density of $1.5 \mathrm{~g} \cdot \mathrm{cm}^{-3}$ from $0 \mathrm{mbsf}$ to $365 \mathrm{mbsf}$ was determined from the density profile of core samples retrieved during the Shimokita cruise. We assumed that the average density for the interval 365-525 mbsf was $1.8 \mathrm{~g} \cdot \mathrm{cm}^{-3}$; therefore, the vertical stress was estimated to be approximately $20 \mathrm{MPa}$. Thus, the magnitudes of the minimum principal stress from the XLOT and the vertical stresses are close to one another, suggesting that we either measured the vertical stress with the XLOT or that we measured the minimum horizontal stress and are in a transitional strike-slip to reverse faulting environment. Since we were not able to determine the attitude of the hydraulic fracture in the test interval, we cannot ascertain which of these two possibilities is correct. Considering the many past applications of XLOT, both in continental scientific drilling projects and in industry oil fields (Kunze and Steiger, 1991; Lund and Zoback, 1999), we suggest that, although it is not a perfect and universally used technique, XLOT can provide data that are both valuable and practical for estimating the magnitude of minimum principal stress (Nelson et al., 2007).

\section{XLOT Procedures for Stress Estimation}

The XLOT procedure that we suggest for determination of stress magnitudes during future riser-drilling programs conducted onboard Chikyu is shown in Fig. 4. This procedure has several advantages over the types of tests often conducted following borehole completion. First, the XLOT procedure is superior to the LOT procedure. It can be difficult to obtain reliable estimates of minimum principal stress by using only the value of LOP, which is the only stress-related parameter obtained by the LOT procedure. Second, we suggest that implementation of multiple XLOT cycles (at least 3 cycles) will provide more reliable results than the LOT or XLOT procedure alone. The first cycle (equivalent to the previously mentioned casing-shoe integrity test) uses a lower maximum injection pressure than the predicted LOP and is designed to estimate the permeability of the formation, determine whether there are pre-existing fracture(s) and weakness(s), and check the effectiveness of cementing. The second cycle is a standard XLOT procedure, and the third cycle is a repetition of the second cycle to confirm the diagnostic pressure values obtained from the previous XLOT.

It is also important to record a high accuracy, closely sampled data set to avoid some of the difficulties in accurately picking test parameters, discussed in the example presented above. Data monitoring and recording details should include pumping pressure, the volume of fluid injected, and the volume of fluid returned to the fluid tank during bleed-off. We think this recording is quite easy. It is also important that the density of the fluid being injected is well known so that the hydrostatic pressure at the casing shoe under in situ pressure and temperature conditions can be calculated; alternatively, down-hole pressure recording at the casing shoe can be employed (using a wireline or memory tool ) to measure directly pressure at the casing shoe.

The procedures that we suggest (Fig. 4) and describe in detail below are similar to those conducted in deep onshore wells (Yamamoto, 2003).

(1) In the first (LOT) cycle, drilling fluid is pumped into the borehole at a constant flow rate (e.g., $0.5 \mathrm{bbl} \cdot \mathrm{min}^{-1}$, or about $80 \mathrm{~L} \cdot \mathrm{min}^{-1}$ ); pumping stops before the expected LOP, and the well is shut-in for $5-10 \mathrm{~min}$. The pressure decline during the very early stage of shut-in reflects the decay of viscous pressure losses in the surface plumbing and drill pipe, and the pressure change during the later stage of shut-in is controlled by the permeability of the formation. If the pressure decline in the late stage of shut-in is large and does not stabilize, the leak-off of fluid might be attributed to the existence of natural fractures or to ineffective cementing. If the casing shoe is too permeable, then the

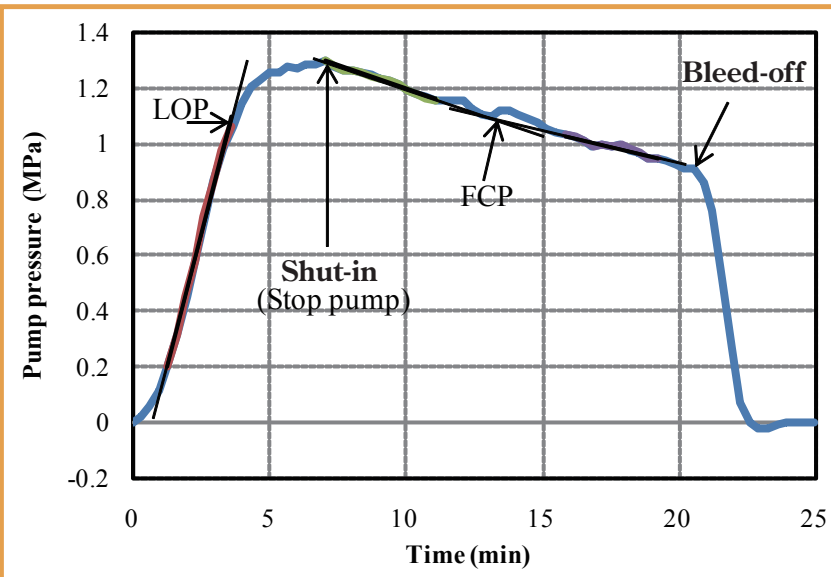

Figure 3. Pumping pressure at drilling rig level versus elapsed time during XLOT carried out on board the riser vessel Chikyu. 


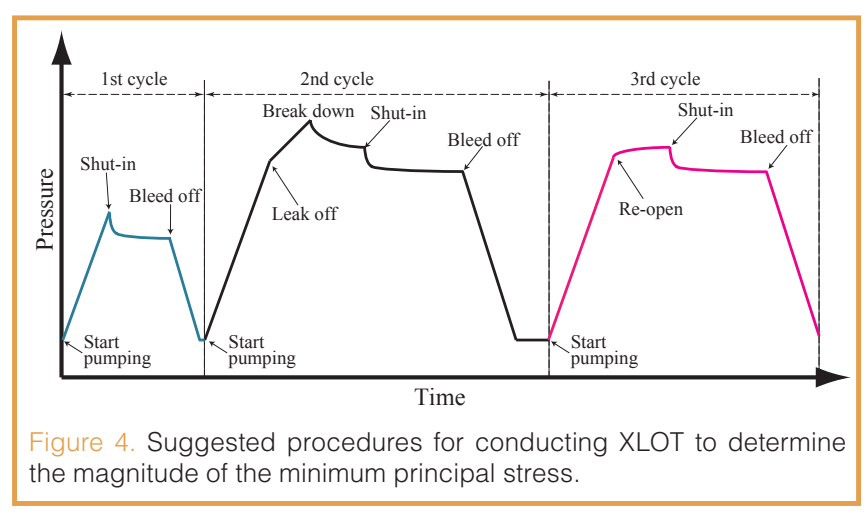

second and third test cycles are unnecessary, as a reliable measure of the minimum principal stress will not be possible.

(2) In the second injection cycle, pumping continues for at least $1 \mathrm{~min}$ beyond formation breakdown, and the well is then shut-in. If formation breakdown is not achieved but pressure decreases during pumping (indicating fracture propagation, perhaps from a pre-existing fracture), then pumping should continue until the volume of fluid injected reaches at least several barrels (e.g., $3 \mathrm{bbl}$, or about $450 \mathrm{~L}$ ) and the well is shut in.

(3) The well then remains shut-in while pressure is monitored for at least $10 \mathrm{~min}$ or until the pressure ceases to decay. The well is then bled off.

(4) To evaluate the pressure versus volume curve during bleed-off, flow-back volume is monitored with a flow meter. The curve shown in Fig. 5 is an idealized relation between pumping pressure and volume, and it indicates the total amount of fluid lost into the formation (or through other system leaks) during the test. Raane et al. (2006) also mentioned that pump-in/flow-back test appears to give a robust estimate of the minimum principal stress.

(5) The third cycle repeats steps 2-4 and allows comparison of the pressure parameters obtained during the second cycle.

(6) Comparison of the pressure decline curves of the third and second cycles provides information about the state of the borehole. For example, if the pressure decline after shut-in during the third cycle is comparable to that observed in earlier cycles, then the cement bond has not been damaged, and with the test interval permeability has not been significantly affected.

(7) If required, a fourth cycle of pumping can be undertaken to investigate borehole integrity, including the extent of formation permeability during the test. In this case, the casing shoe is again pressurized to the maximum pressure of the first cycle. The well is then shut in, and the pressure and fluid volume monitored. Comparison of the pressure build-up rate (pressure versus volume) during injection and the pressure decline after shut-in during this cycle with those of the first cycle will show whether or not borehole integrity has been compromised.

There may be concern that the new fracture created during the XLOT has affected casing-shoe integrity. In general, casing-shoe integrity is maintained if appropriate drilling fluid (mud) has been used (Morita et al., 1997).

Calculation of minimum principal stress by using LOTXLOT data depends on the assumption that a new fracture is created in a plane perpendicular to the minimum principal stress by the pumping pressure and that pre-existing fracture(s), weakness(s), anisotropy, and heterogeneity of the formation have no significant influences. Therefore, knowing with certainty the attitude of the new fracture produced is very helpful to determine direction of the minimum principal stress. For this purpose, Fullbore Formation Microimager (FMI) and/or Ultrasonic Borehole Image (UBI) logs or impression packer before and after the test can be conducted to acquire borehole images in cases of hydraulic fracturing which is conducted not at the borehole bottom (casing shoe). However, it should be difficult in case of an XLOT before the test because its test interval is too short to allow installing of FMI- or UBI-type logs. Additionally, in many cases the resolutions of FMI or UBI images are too low to see a hydraulic fracture. Also, given the low probability of success, it is hard to justify the expense and rig time for running a log to image a 1-3 $\mathrm{m}$ section of borehole.

The minimum principal stress determinate by an XLOT is equivalent to minimum principal horizontal stress in normal and strike-slip faulting environments; and hydraulic fracture is induced in a vertical plane. In contrast, in reverse faulting environments the minimum principal stress is equivalent to vertical stress; the fracture is formed in a horizontal plane. In general, it is difficult to identify if the minimum principal stress is vertical or horizontal stress without knowing attitude of hydraulic fracture induced. Only in cases where the minimum principal stress from an XLOT is significantly lower in magnitude than the calculated vertical stress, can the minimum principal stress be identi-

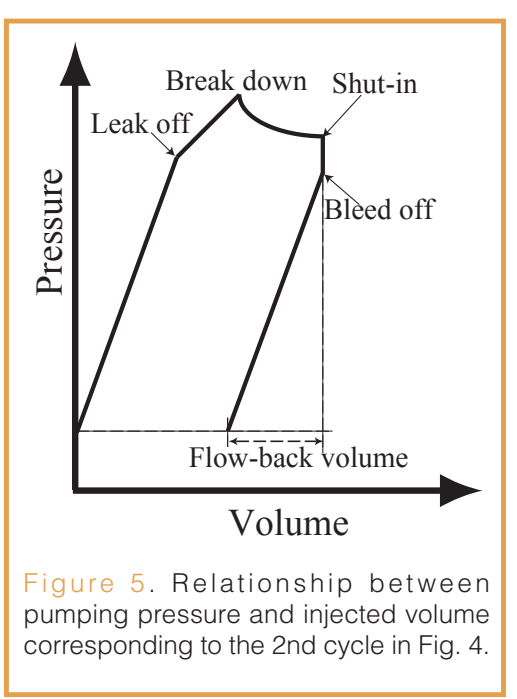

fied as the minimum horizontal stress.

A drawback of the XLOT procedure that we have recommended is that it cannot be used to determine the magnitude of maximum principal stress, which is also difficult to determine using the standard hydraulic fracturing test (Ito et al., 2007). 
The magnitude of the maximum principal stress in deep wells is best practically determined through an integrated analysis of borehole breakouts and tensile fractures from image logs, rock strength, and the minimum principal horizontal stress from the XLOT, as discussed, for example, in Zoback et al. (2003). However this integrated analysis has several problems which should be solved in the near future, such as rock strength problem (Haimson and Chang, 2002) and the effect of fluid compressibility and compliance of the test system (Raaen et al., 2006). In the near future, it is preferable and hopeful that more reliable and robust in situ stress measurements will be developed and applied onboard the Chikyu.

\section{Summary}

Investigation of in situ stress at depth is a necessary and important outcome of IODP drilling programs such as NanTroSEIZE. Fortunately, the availability of the new research vessel Chikyu means that LOT and XLOT procedures can be readily undertaken during future riser-drilling programs; these will yield important information about in situ stress magnitude as well as providing some of the data needed for drilling operations (e.g., borehole stability analysis). We used data from the 2006 Chikyu Shimokita shakedown cruise to demonstrate the feasibility of using XLOT data to determine the magnitude of the in situ minimum principal stress at depth. The procedures that we have recommended for the application of XLOT to determine stress magnitude during future riser-drilling programs of the Chikyu represent the most important outcome of this work.

\section{Acknowledgements}

We thank the Chikyu drilling operation team for allowing us to use XLOT data acquired by them during the Shimokita cruise. We gratefully acknowledge Stephen Hickman for his careful reviewing and many constructive comments which greatly improved the manuscript. This work was partly supported by Grant-in-Aid for Scientific Research (C: 19540453) of the Japan Society for the Promotion of Science.

\section{References}

Addis, M.A., Hanssen, T.H., Yassir, N., Willoughby, D.R., and Enever, J., 1998. A comparison of leak-off test and extended leak-off test data for stress estimation, SPE/ISRM 47235. Proc. SPE/ ISRM Eurock 98, Volume 2, Trondheim, Norway, 8-10 July 1998, pp. 131-140.

Haimson, B.C., and Chang, C., 2002. True triaxial strength of the KTB amphibolite under borehole wall conditions and its use to estimate the maximum horizontal in situ stress. $J$. Geophys. Res., 107(B10):2257, doi:10.1029/2001JB000647.

Hickman, S., Zoback, M.D., and Benoit, R., 1998. Tectonic controls on fault-zone permeability in a geothermal reservoir at Dixie Valley, Nevada. In Holt, R.M., et al. (Eds.), Rock Mechanics in Petroleum Engineering, vol. 1, Richardson, Texas (Society of Petroleum Engineers), 79-86.

Ito, T., Omura, K., and Ito, H., 2007. BABHY - A new strategy of hydrofracturing for deep stress measurements. Sci. Drill., Special Issue, 1:113-116.

Kinoshita, M., Tobin, H., and Moe, T., 2008. Preliminary results from NanTroSEIZE IODP Expedition 314, LWD Transect across the Nankai Trough off Kumano. Japan. Geoscience Union Meeting 2008, Chiba, Japan, 25-30 May 2008, U054-004.

Kunze, K.R., and Steiger, R.P., 1991. Extended leak-off tests to measure in situ stress during drilling. In Roegiers, J.-C. (Ed.), Rock Mechanics as a Multidisciplinary Science. Rotterdam (Balkema) 35-44.

Lin, W., Kwasniewski, M., Imamura, T., and Matsuki, K., 2006. Determination of three-dimensional in situ stresses from anelastic strain recovery measurement of cores at great depth. Tectonophysics, 426:221-238, doi: 10.1016/j. tecto.2006.02.019.

Lund, B., and Zoback, M.D., 1999. Orientation and magnitude of in situ stress to $6.5 \mathrm{~km}$ depth in the Baltic Shield. Int. J. Rock Mech. Min. Sci., 36:169-190.

Morita, N., Fuh, G.-F., and Boyd, P.A., 1997. Safety of casing-shoe test and casing-shoe integrity after testing. SPE Drilling \& Completion, 12:266-274.

Nelson, E.J., Chipperfield, S.T., Hillis, R.R., Gilbert, J., McGowen, J., and Mildren, S.D., 2007. The relationship between closure pressures from fluid injection tests and the minimum principal stress in strong rocks. Int. J. Rock Mech. Min. Sci., 44:787-801.

Raaen, A.M., Horsrud, P., Kjorhold, H., and Okland, D., 2006. Improved routine estimation of the minimum horizontal stress component from extended leak-off tests. Int. J. Rock Mech. Min. Sci., 43:37-48.

Tobin, H., and Kinoshita, M., 2007. The IODP Nankai Trough Seismogenic Zone Experiment, Sci. Drill., Special Issue, 1:39-41.

White, A.J., Traugott, M.O., and Swarbrick, R.E., 2002. The use of leak-off tests as means of predicting minimum in situ stress. Pet. Geosci., 8:189-193.

Yamamoto, K., 2003. Implementation of the extended leak-off test in deep wells in Japan. In Sugawara, K. et al. (Eds.), Proceedings of the Third International Symposium on Rock Stress Rs, Kumamoto '03, Rotterdam (Balkema), 225-229.

Zoback, M.D., Barton, C.A., Brudy, M., Castillo, D.A., Finkbeiner, T., Grollimund, B.R., Moos, D.B., Peska, P., Ward, C.D., and Wiprut, D.J., 2003. Determination of stress orientation and magnitude in deep wells. Int. J. Rock Mech. Min. Sci., 40:1049-1076.

\section{Authors}

Weiren Lin, Kochi Institute for Core Sample Research, Japan Agency for Marine-Earth Science and Technology, Nankoku 783-8502, Japan, e-mail: lin@jamstec.go.jp

Koji Yamamoto, Technology Research Center, Japan Oil, Gas and Metals National Corporation, Chiba, Japan

Hisao Ito, Hideki Masago, and Yoshihisa Kawamura, Center for Deep Earth Exploration, Japan Agency for MarineEarth Science and Technology, Yokohama, Japan 